\title{
MRSA admission burden and acquision in a tertiary care hospital
}

\author{
H-MA Schmidt ${ }^{*}$, E Ryan ${ }^{2}$, MW Maley ${ }^{1}$, SJ van $\mathrm{Hal}^{1}$ \\ From International Conference on Prevention \& Infection Control (ICPIC 2011) \\ Geneva, Switzerland. 29 June - 2 July 2011
}

\section{Introduction / objectives}

The burden of methicillin-resistant Staphylococcus aureus (MRSA) impacts on the effectiveness of infection control strategies to prevent MRSA transmission. Few studies examining the admission and acquisition burden of MRSA exist. We investigated the prevalence of MRSA in patients admitted to a tertiary referral hospital that does not conduct universal screening, to determine the MRSA admission burden and acquisition rate.

\section{Methods}

Nasal swabs were collected for MRSA culture on admission $(n=1159)$ and discharge $(n=373)$ from patients admitted to acute adult wards. Strain typing for similarity was performed using antibiograms and pulsed field gel electrophoresis (PFGE).

\section{Results}

The overall MRSA admission burden was $10.9 / 100$ admissions. This consisted of patients identified by nasal swabs (3.5/100 admissions) or clinical samples (1.1/100 admissions) collected within 48 hours of admission; and those with a known history of MRSA colonisation (6.2/ 100 admissions). During the study period, 1.7 new MRSA acquisitions per 100 admissions were detected in patients who had exit sampling. Of these, $83 \%$ represented colonisation events with the remaining $17 \%$ clinical infections. MRSA acquisition was associated with longer hospital stays $(\mathrm{p}<0.01)$.

\section{Conclusion}

Despite a high MRSA admission burden, the rate of acquisition was modest. $67 \%$ of the total MRSA burden was identified without universal screening and could be

${ }^{1}$ Microbiology and Infectious Diseases, Sydney South West Pathology Service, Liverpool Hospital, Sydney, Australia

Full list of author information is available at the end of the article isolated. However, existing strategies for controlling MRSA are resource and cost intensive. Furthermore, nasal carriage represents an unrecognised reservoir for the transmission of MRSA to new patients, the relative importance of which must be considered. Further exploration of the factors underlying the acquisition rate will assist in identifying strategies to prevent MRSA transmission.

\section{Disclosure of interest}

None declared.

\section{Author details}

${ }^{1}$ Microbiology and Infectious Diseases, Sydney South West Pathology Service, Liverpool Hospital, Sydney, Australia. ${ }^{2}$ Infection Prevention Unit, Liverpool Hospital, Sydney, Australia.

Published: 29 June 2011

doi:10.1186/1753-6561-5-S6-080

Cite this article as: Schmidt et al:: MRSA admission burden and acquision in a tertiary care hospital. BMC Proceedings 2011 5(Suppl 6): O80.

Submit your next manuscript to BioMed Central and take full advantage of:

- Convenient online submission

- Thorough peer review

- No space constraints or color figure charges

- Immediate publication on acceptance

- Inclusion in PubMed, CAS, Scopus and Google Scholar

- Research which is freely available for redistribution

\section{() Biomed Central}

